\title{
Optimal selection of agricultural crops for sustainable farming in nutrient-rich Wadi areas of Saudi Arabia using MCDM
}

\author{
Vineet Tirth*****, Ram Karan Singh**, Saiful Islam *** and Ali Algahtani * \\ * Mechanical Engineering Department, College of Engineering, King Khalid University, Guraiger, Abha, Asir, Kingdom of Saudi Arabia \\ Research Center for Advanced Materials Science (RCAMS), King Khalid University, Guraiger, Abha, Asir, Kingdom of Saudi Arabia \\ ** Department of Civil \& Environmental Engineering, The NorthCap University, Gurugram, India \\ *** Civil Engineering Department, College of Engineering, King Khalid University Guraiger, Abha, Asir, Kingdom of Saudi Arabia \\ ***** Corresponding Author : v.tirth@gmail.com
}

Submitted : 29/07/2019

Revised :28/09/2020

Accepted : 16/10/2020

\begin{abstract}
In the Kingdom of Saudi Arabia (KSA), Wheat, Barley, fruits, vegetables, and fodders are the most common agricultural products. Agricultural sustainability depends on socioeconomic and climatic conditions. Proper crop selection is vital to maximize productivity, yielding more revenue to the farmer at a lower cost. To rank the crop alternatives based on the available natural resources and cost, a multicriterion based decision-making model (MCDM) may be applied to identify the best suitable crop, encouraging sustainable agricultural practices. To make the agricultural activities sustainable, most of the critical criteria are taken into account. Four criteria linked to sustainability are included in this study. The research focuses on developing a model for sustainable agricultural practices in KSA employing MCDM. Three MCDM techniques were employed to evaluate the most suitable crop, and the results are compared and validated. The results from all three methods gave consistent results. Fruits emerged as the most productive crop, followed by Wheat, vegetables, fodders, and Barley. Such methodology shall be further extended across the other regions and over various crops for sustainable agricultural practices. The study is expected to help the Ministry of Water, Environment, and Agriculture, KSA, draft a suitable agricultural policy.
\end{abstract}

Keywords: Natural resources; Agricultural policy; Crop productivity; Crop ranking; Crop productivity.

\section{INTRODUCTION}

Based on the demographic criteria, identifying the most profitable crop is hugely beneficial for sustainable farming (Nambiar et al., 2001). Nowadays, the agricultural activities are becoming highly mechanized with green chambers and precision farming system while conserving and optimizing the available natural resources. The sprinkler and drip irrigation is an innovative example of water conservation practice. To cater to the rapid population growth, there is a need for an increase in yield per unit of land (Pramanik, 2016). To manage the mismatch of demand and supply, sustainable crop production activities have become increasingly significant (Rao et al., 2011). The 
improvement and development of people's quality of life and conserving earth's natural resources are the need of the hour (Cocklin, 2009). The sustainable agricultural activities are linked with the socio-, economic, and natural resources. These things are closely related to the farmers' self-reliance and personal satisfaction (Peacock et al., 2010). The economic aspects of the farmers involve crop yield and its market value. The environmental condition of the arid zone is challenging due to less rainfall and high temperature. The agricultural products help guarantee food security and contribute to a country's development (Bailey et al., 2013). As per the Food and Agriculture Organization (FAO), the natural soil nutrient, the crop yield's market value, the water quality, and the carbon credits are the essential elements in the agricultural output.

In the Kingdom of Saudi Arabia (KSA), the most grown crops are fruits (primarily dates), vegetables, Wheat, Barley, and fodder. Farmers also nurture poultry products and milk as a supplementary source of income. Once selfsufficiency is achieved, the agricultural products may be exported to complement KSA's much-aspired oilindependent economy. The Ministry of the Environment, Water, and Agriculture, in which agriculture is the primary division, is responsible for framing the significant policies to encourage the community towards entrepreneurship. The government in KSA offers loans, maintains the supply of water, electricity, and fuel at a subsidized rate, and facilitates machinery and materials imports. Though highly skilled and laborious, the farmers are often less educated and so need technical advice to maximize productivity. The principle restricting variables to cultivation in KSA are soil and water, primarily dominated by deserts, and the cultivatable land is limited, and so are the water resources. Therefore, it is crucial to advance the technologies and simultaneously educate and support the agriculturalists with sustainable cultivating practices, optimizing natural resources, conservation of water, better crop seeds, and, most importantly, proper crop selection and rotation. Right from the field preparation, sowing, curing at the different stages, maintaining optimum moisture and soil nutrients, and adding appropriate quantity and type of manure at the right stages of harvesting are the factors that directly control the yield. Over and above, if the proper crop selection is made to best suit the available resources and the market demand, the farmers' profitability may be maximized, maintaining a high yield. The sustainable criteria discussed above have a significant role in crop ranking (Garg et al., 2014).

The annual average rainfall of the KSA is low compared to the world average, so the available irrigation water is the scarce resource. Hence, the irrigation systems are required to be the same in precision farming activities, such as sprinkler and drip irrigation systems. To benefit the entire stakeholders, proper agricultural management skills are needed to be adopted, and the appropriate crop selection will be an effective strategy. To manage better marketing strategies and operating activities, enough budget needs to be allocated. The criteria related sustainability of farming was first inducted (Gowda et al., 1998) and later extended by Qureshi et al. (2018). A new approach to sustainability, which was the index-based concept, was introduced (Dillon et al., 2009).

The concept of mathematical computation of farm sustainability was inducted (Zhen et al., 2005). The natural health of the soil and its nutrient content management, both natural and artificial, was also inducted (Zhen et al., 2006). The socioeconomic, environmental concept, simulation, and modeling were inducted (Sydorovych et al., 2008). In Bangladesh, the indicators related to farm sustainability were examined (Roy et al., 2012). A study was presented to harvest selection in the agricultural landscape (Sorensen et al., 2015). The several areas where MCDM were used are hydrologic cycle, environmental system, floodwater management, management of water resources, city water supply system, water quality management, etc., by different researchers (Behzadian et al., 2010; Srdjevic et al., 2004; Raju et al., 2000; Chitsaz et al., 2015; Mutikanga et al., 2011; Raju et al., 2007; Carroll et al., 2013; Roozbahani et al., 2012; Singh et al. 2019; \& Warrag et al. 2019). The MCDM techniques were used in energy sectors (Garg et al., 2007), industrial systems (Rao et al., 2010), in robotics (Bhangale et al., 2004), domestic and industrial waste management problems (Srinivan et al., 2017), and estimation of water quality (Agarwal et al., 2016). The MCDM was also inducted with dimensional and nondimensional criteria (Rao et al., 2010; Song et al., 2016; Venkata, 2008 \& Geng et al., 2013). Other applications of MCDM included the selection of a sustainable supplier for efficient supply chain management (Hendiani et al., 2020), selection of suitable biomass for maximizing the yield of biofuel 
(Madhu et al., 2020), selection of proper stone and sawaqbility in construction (Kamran et al., 2017), and selection of the most appropriate site for the wind farms (Xu et al., 2020).

In KSA, the systems approach for selecting a suitable crop under the given natural resources has not been explored before. Application of mathematical techniques such as MCDM may provide useful guidelines to the farmers for maximizing productivity at the optimum use of natural resources. This research work aims to formulate the MCDM model for preferred crops in southwest KSA. The five general crops selected are Barley, Wheat, vegetables, fruits, and fodders. MCDM techniques used are VIKOR, TOPSIS, AHP, Exprom2, and Entropy. The four sustainable criteria are the crop field area, the yield of the crops, cultivation cost, and market value of the crop. The farm area's soil condition is of the arid region, having the texture of clay loam, sandy clay loam. The research objectives of the present work are based on the integration of the systems approach using the MCDM methods for weighing critical criteria and crop selection in the nutrient-rich Wadi areas of Asir province in KSA. The literature review identifies critical criteria and alternative crops. Each criterion is then assigned weights by two MCDM methods, followed by the assignment of compound weights. The normalization will help in obtaining a versatile result. Finally, three MCDM ranking methods will be applied to rank the crop alternatives and validate the results simultaneously.

\section{MATERIALS AND METHODS}

\section{Study Domain}

Though the significant part of Saudi Arabia is desert, it has certain local regions called Wadi, which have nutrient-rich soil and suitable moisture for agricultural activities, even though the average annual precipitation is deficient. In the Wadi area, most of the run-off water flows through. The average annual rainfall is close to $100 \mathrm{~mm}$, except in the southern region, close to the Red Sea, which is more than the country's average. In this region, many dams are constructed for water storage, being used as a precious natural resource during water scarcity. To improve the national agricultural industry, the government implemented the multifaceted program to commercialize and modernize agricultural activities in late 1970 and early 1980. The agricultural land of KSA and the conflict with the urban population is presented in Figure 1 (General crop pattern, 2019).

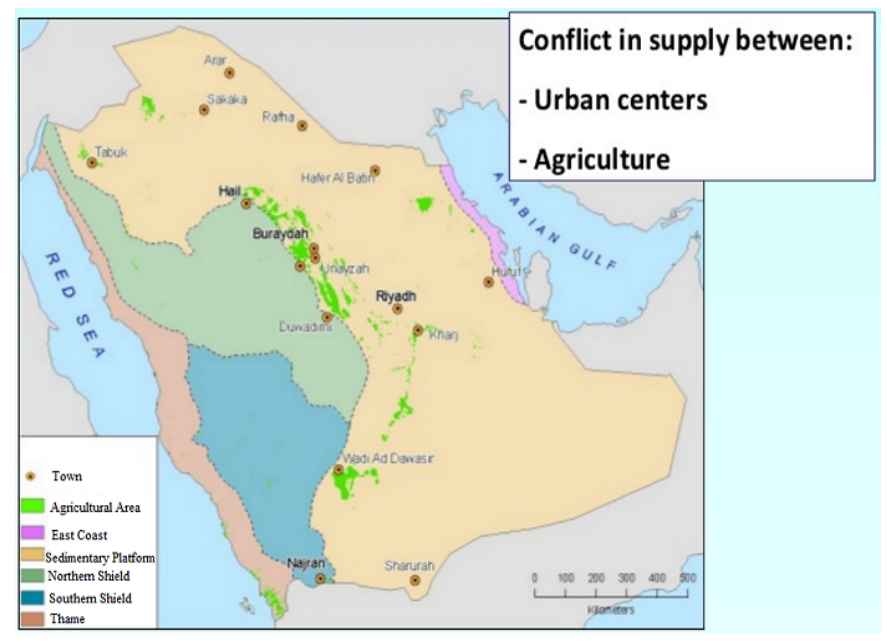

Figure 1. The General Crop area pattern of the Study area (General crop pattern, 2019). 
The study's scope includes the selection of five alternative crops, namely, Wheat, Barley, Vegetables, Fruits, and Fodder, for a preferential ranking using MCDM. The four criteria determine the harvest, cost of production, and natural resources identified as the crop field area, crop field production (harvest), cost of production, and price of sales. Among these criteria, the cost of production and the market value of the crop are nonbeneficial factors. In contrast, the farm area availability and the crop yield per unit farm area are the beneficial attributes. Crop production is the primary function of soil health. If the soil is weak in natural nutrients, then the artificial manures, and the fertilizers are used for this purpose, and subsequently, it makes the harvesting process expensive. In the regional scale formulation of this problem, the limiting factors are the farm area's availability for the particular crop, the production of the crop per unit farm area, the sales price of the crop after harvest, and the irrigation water requirement. Water is an essential resource for irrigation, but it is scarce in the middle east region (Aleisa and Alshayji, 2019), so it has not been considered as criteria.

The ranking of the crops is a crucial decision to benefit the farmers and other end users. The sustainability, climatic conditions, and socioeconomic constraints are crucial factors for the Ministry of Agriculture policymakers. The chart in Figure 2 demonstrates the process of crop ranking implemented in the present study. At first, the alternative crops and the related criteria are identified. Second, a decision matrix is developed, and the weights to the criteria are assigned. Third, the three MCDM techniques are applied, and the preferential score of the crops is estimated. Fourth, the crops are ranked with each method, and the rank is validated by comparison of results. Finally, the best suitable crop is selected.

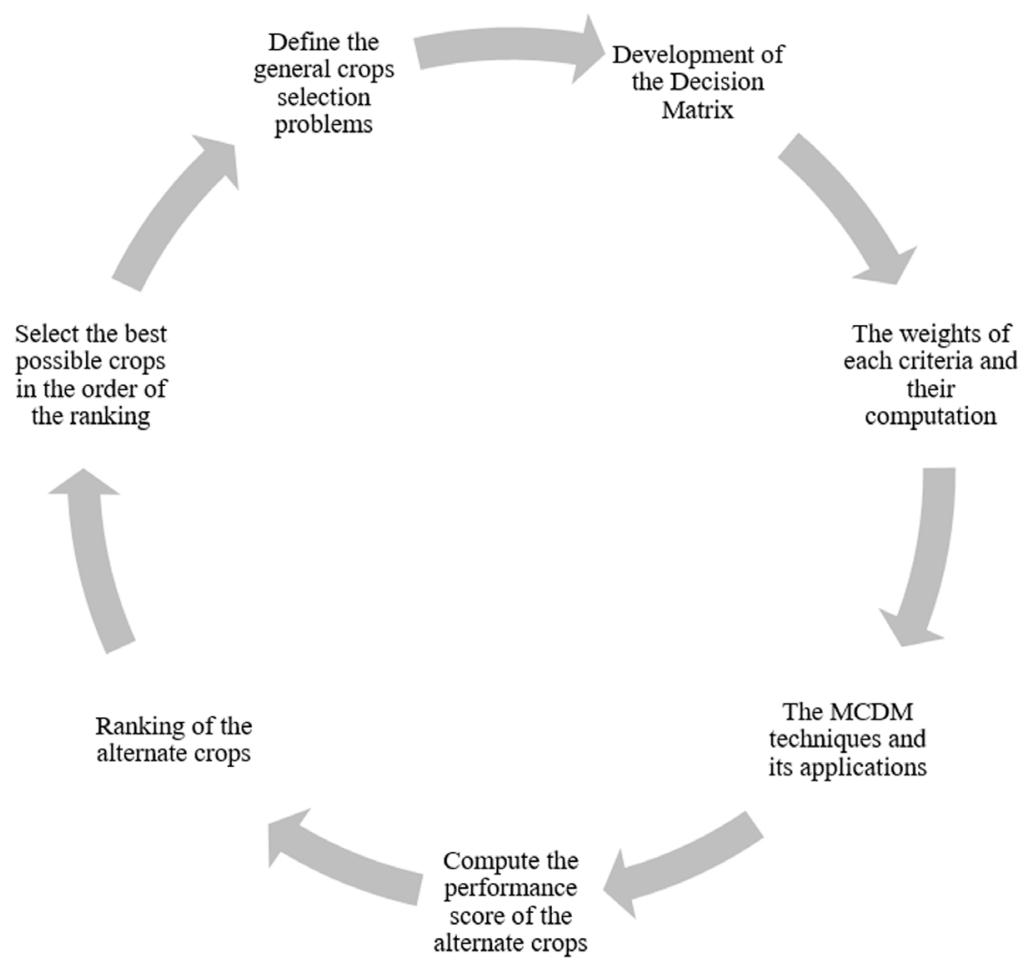

Figure 2. The Steps of the Ranking process for general crop selection using MCDM.

The system approach integrated with the MCDM using critical criteria for the crop selection is used for the first time in this paper in KSA. 


\subsection{The MCDM Methods}

\subsubsection{Criteria Weighting}

The Analytic Hierarchy Process (AHP) and Entropy joint criteria weight equation are used to obtain a better average.

$$
w_{k}=\frac{\alpha_{k X \beta_{k}}}{\sum_{j=1}^{n} \alpha_{k X \beta_{k}}} k=1,2, \ldots, n
$$

Here, wk is the synthesis weight, $\alpha \mathrm{k}$ is the weight of kth criteria computed by AHP, and $\beta_{k}$ is then computed by the Entropy method (Chu et al., 2012).

\subsubsection{AHP method}

The first AHP method was proposed (Wind et al., 1980), which was further extended, and later, a three-step synthesis was given (Dağdeviren et al., 2009), in Eq. (2) to (4).

$$
A=\left[\begin{array}{ccc}
a_{11} & \cdots & a_{1 n} \\
\vdots & \ddots & \vdots \\
a_{1 n} & \cdots & a_{n n}
\end{array}\right], \quad a_{i i}=1, a_{i j}=1 / a_{j i}, a_{j i} \neq 0
$$

Here, $\mathrm{A}$ is the matrix, and $a_{1}, a_{2}$, etc. are the criteria.

The consistency ratio (CR) and the consistency index (CI) are calculated from the following equations to ascertain the uniformity of the subjective perception and the comparative weights' consistency. In this, $n$ is the criteria. The consistency index is $<0.1$ for the results to be consistent, and RI should be less than 0.1 for the reliable result (Hamidi et al., 2010).

$$
\begin{aligned}
& C R=\frac{C I}{R I} \\
& C I=\left(\lambda_{\text {max }}-n\right) /(n-1)
\end{aligned}
$$

In Eq. (4), $\lambda_{\max }$ is the highest eigenvalue of decision matrix $A$, and $\mathrm{n}$ is the number of criteria (evaluation indexes).

\subsubsection{Entropy Method}

The entropy method is used to determine the uncertainty related to the data used in the formulation of probability theory. Figure 3 gives the AHP and Entropy methods in a flow chart to calculate the hybrid weight $w_{k}$. In the decision matrix A, where there are $m$ choices and $n$ criteria, $x_{11}, x_{1 n}$, etc. are evaluation indices (Wind et al., 1980; Dagdeviren et al., 2009; Hamidi et al., 2010). To compare different dimensionless criteria, the normalization matrix elements are computed, where $P_{i j}$ is the normalized vector, used to compute the entropy $E_{j}$ of the $j^{\text {th }}$ criteria. A constant ensures $0 \leq E_{j} \leq 1$ in the $k=1 / \ln m$, where m presents the number of choices, and $d_{j}$ is the degree of divergence of the average information found in every criterion: the $k^{\text {th }}$ criteria entropy weight, $\beta_{k}$. 


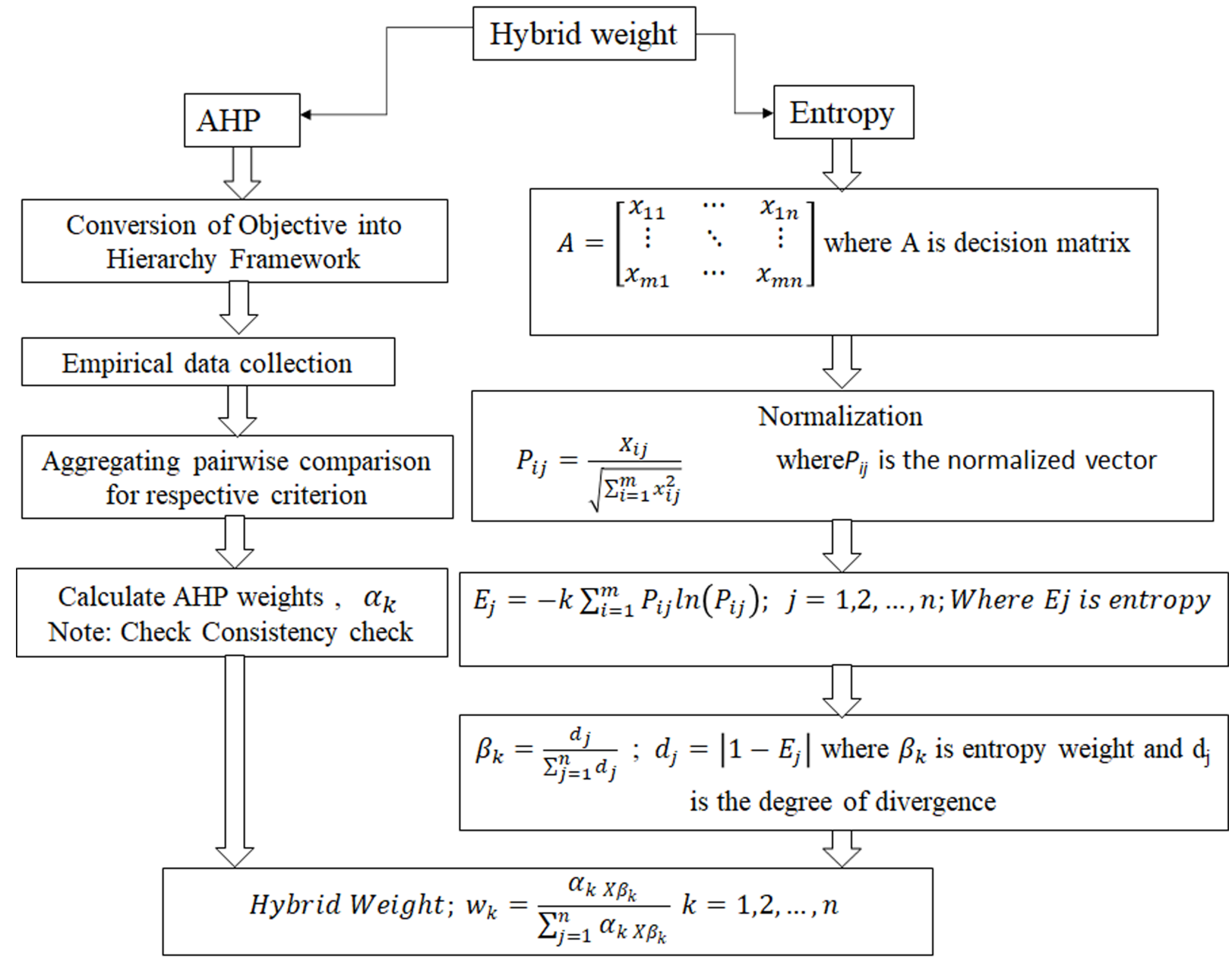

Figure 3. AHP and Entropy methods of criteria weight assignment

(Wind et al., 1980; Dağdeviren et al., 2009; Hamidi et al., 2010).

\subsubsection{EXPROM2 Method}

The EXPROM2 method is the revised version of the PROMETHEE II method. This is based on the ideal and anti-ideal solutions. The method's steps were developed (Chatterjee et al., 2012; Doumpos et at., 2004; Raju et al., 1999), shown in the flow chart in Figure 4.

The intermediate steps are clubbed, and the final version of the equation is used to select the best possible alternative, depending on the value of $\varphi(i)$. Here, $\varphi(i)$ is the total outranking flow, $\varphi^{+}(i)$ is the positive flow, and $\varphi^{-}(i)$ is the $i^{\text {th }}$ alternative's negative flow. 


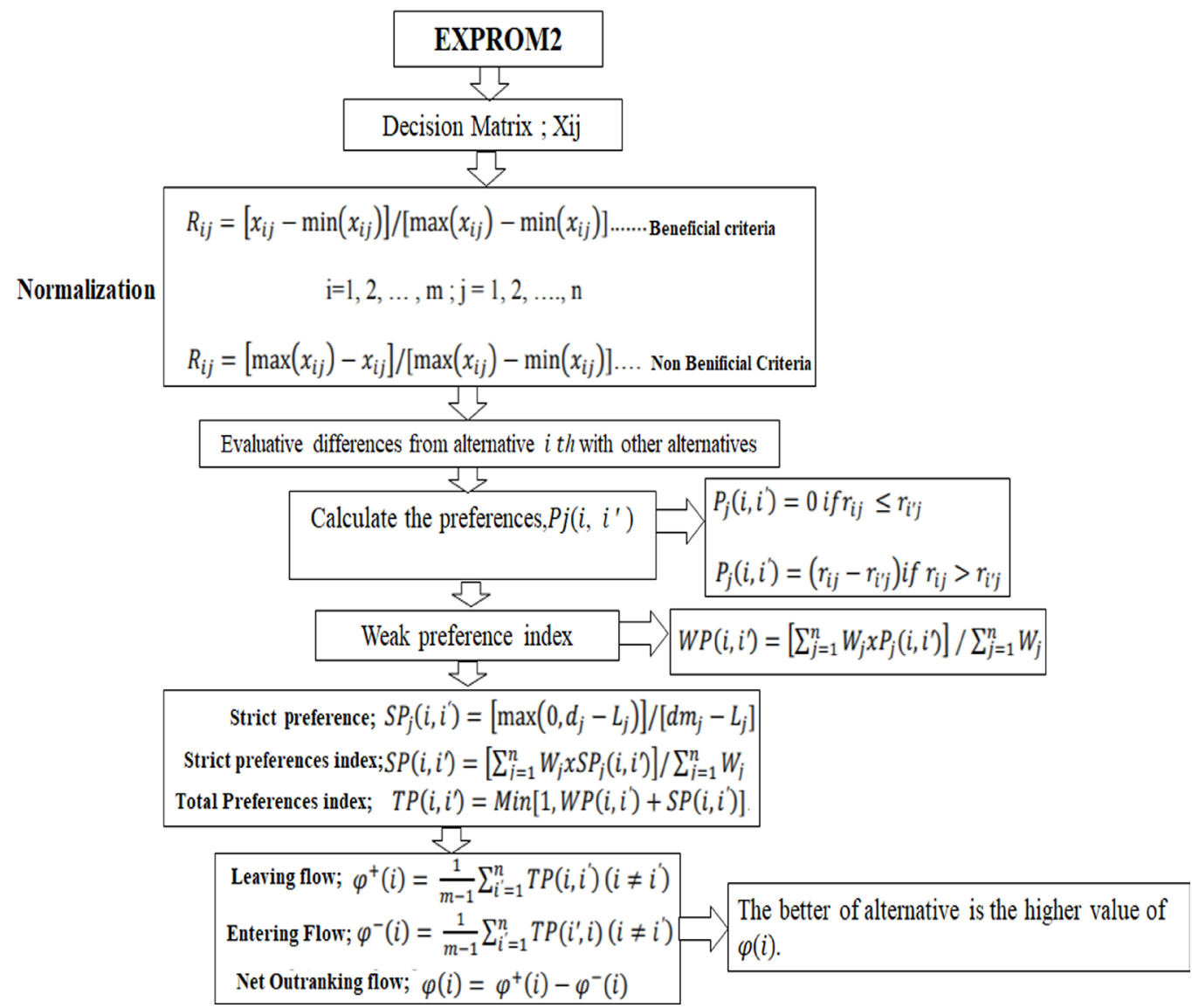

Figure 4. EXPROM2 method of MCDM (Chatterjee et al., 2012; Doumpos et at., 2004; Raju et al., 1999).

\subsubsection{The Technique for Order of Preference by Similarity to Ideal Solution (TOPSIS) Method}

The computation steps involved in the TOPSIS process are given chronologically in Figure 5.

The first step is the computation of the evaluation matrix with $m$ choices, and $n$ criteria form the matrix $\left(x_{i j}\right)_{m x n}$, and the intersection point of each choice is represented by $x_{i j}$. In this matrix, both the nondimensional and dimensional units are included. This is the decision matrix having dimension $m x n$. The second step is the computation of the relative importance matrix to estimate the relative position of one attribute with the other for estimating each criterion's weight under study (Rao et al., 2011 \& Wind et al., 1980). The third step is the computation of the normalized decision matrix $\left(x_{i j}\right)_{m x n}$ as $R$ by using the normalization matrix $r_{i j}$. The fourth step is the computation of evaluation matrix $T$. Fifth step includes computation of the worst $\left(A_{w}\right)$ and best $\left(A_{b}\right)$ conditions, where $J_{+}$has a positive impact, and $J_{-}$has a negative impact. After that, $d_{i w}$ and $d_{i b}$ are estimated, representing the deviations of the target option $i$ from the worst and best conditions, respectively. Finally, in the sixth step, the Euclidean distance $S_{i w}$ is calculated, ranging from 0 to 1 from the worst and the best conditions. 


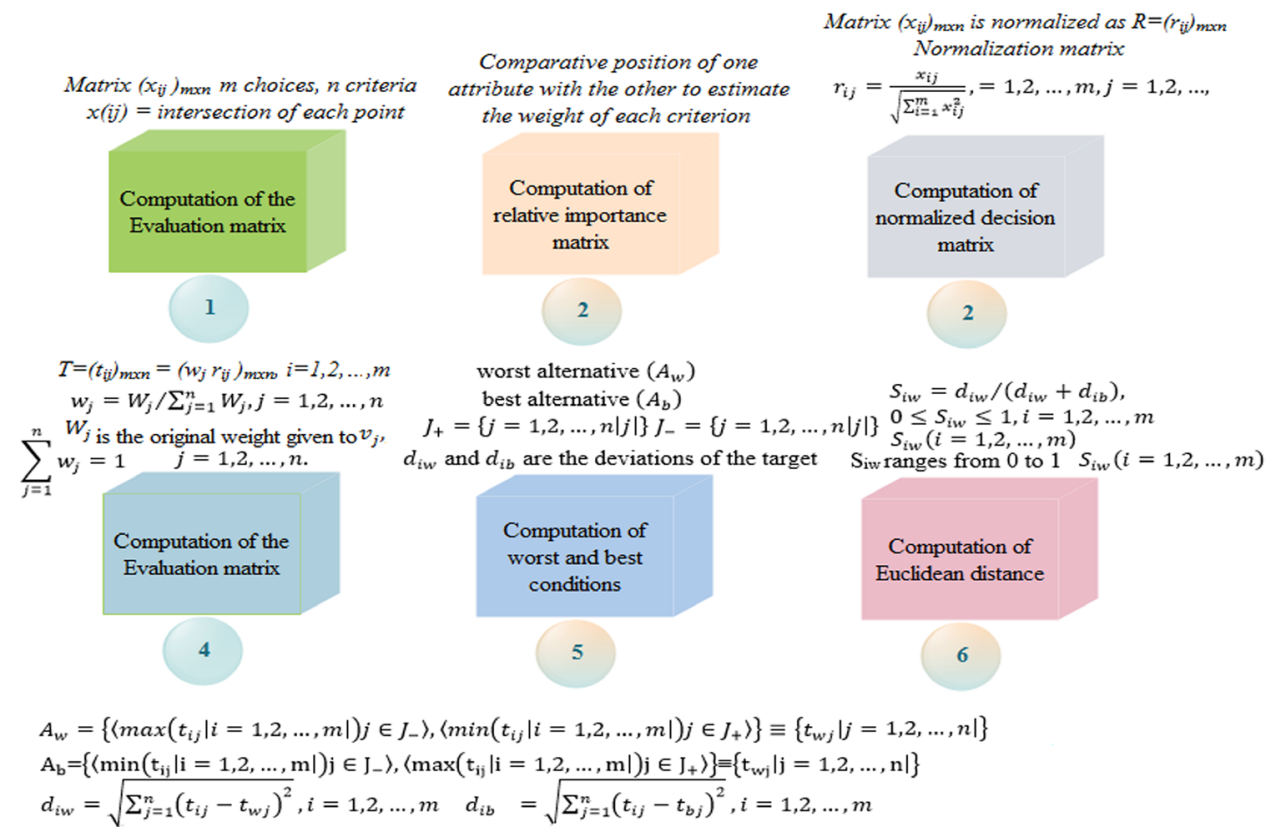

Figure 5. TOPSIS method of MCDM (Rao et al., 2011 \& Wind et al., 1980).

\subsubsection{VIKOR Method}

The VIKOR method is an MCDM technique that gives a compromised solution (Rao et al., 2011). It has three steps to compute the parameters $P i, E_{i}$, and $F_{i}$, as shown systematically in Figure 6.

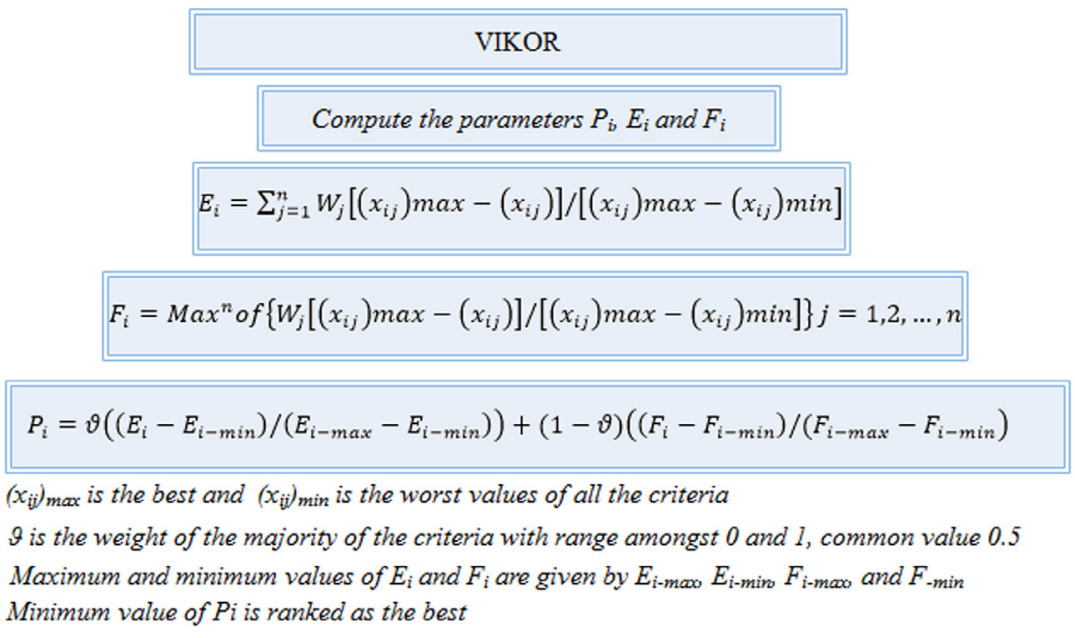

Figure 6. VIKOR method of MCDM (Rao et al., 2011).

Here $\left(x_{i j}\right)_{\max }$ is the best, and $\left(x_{i j}\right)_{\min }$ is the worst values of all the criteria. $\vartheta$ is the weight of most of the criteria with range amongst 0 and 1 , and the typical value is taken as 0.5 . The maximum and minimum values of $E_{i}$ and $F_{i}$ are given by $E_{i-\max }, E_{i-\min }, F_{i-\max }$, and $F_{-\min }$, respectively. 
The ranking table is prepared by arranging the values of $P_{i}, E_{i}$, and $F_{i}$ in the ascending order. The one with the minimum value of $P_{i}$ is ranked as the best.

\section{RESULTS AND DISCUSSION}

Table 1 gives the abbreviations and definitions of the criteria included in this study.

Table 1. The definition of the important criterion used in the study.

\begin{tabular}{|c|l|l|}
\hline Abbreviations & \multicolumn{1}{|c|}{ Criterion } & \multicolumn{1}{c|}{ Definition } \\
\hline CFP & $\begin{array}{l}\text { Production } \\
\text { of Crop } \\
\text { Field }\end{array}$ & $\begin{array}{l}\text { Production of crops in tons per unit } \\
\text { land area. For wheat, it is } 6100 \\
\text { Kg/ha. }\end{array}$ \\
\hline CFA & $\begin{array}{l}\text { Area of crop } \\
\text { Field }\end{array}$ & $\begin{array}{l}\text { The Kingdom of Saudi Arabia } \\
\text { where agricultural land is } 22.5 \% \text { of } \\
\text { the total area. }\end{array}$ \\
\hline CP & $\begin{array}{l}\text { Cost of } \\
\text { Production }\end{array}$ & $\begin{array}{l}\text { Expenses incurred in the production } \\
\text { of crops per unit area. For wheat, it } \\
\text { is 350 USD/ha. }\end{array}$ \\
\hline PS & Price of Sale & $\begin{array}{l}\text { This is the cash return of crop. For } \\
\text { wheat it is around 0.4 USD/Kg. }\end{array}$ \\
\hline
\end{tabular}

Based on the data obtained from the Ministry of Water, Environment, and Agriculture, Govt. of KSA, the MCDM model has been developed to select the best suitable crop under the given criteria. Table 2 summarizes the data used for this purpose having dimensions in appropriate units. The crops chosen for this study's ranking are the available crops typically grown in the Wadi region of southwest KSA. In the Wadi region, the soil's moisture content, texture, and nutrient content are better for agricultural activities. Though the average annual rainfall is low, the available ground and surface water are used for irrigation. The five crops selected for sustainable ranking are Wheat, Barley, Vegetables, Fruits, and Fodder. The codes C1 to C5 have been assigned to the crops. Parameters CFA in hectares, CFP in $\mathrm{kg} / \mathrm{Ha}, \mathrm{CP}$ in USD/Ha, and PS in USD/kg are given for each crop in Table 2. The price has been converted from Saudi Riyals to USD. The choice options C1 to C5 are used for these crops to depict in the database. 
Table 2. The data of general Crops in southwest KSA (Ministry of Agriculture, 2019).

\begin{tabular}{|c|c|c|c|c|c|}
\hline S. No. & $\begin{array}{c}\text { Cash Crops used } \\
\text { (Alternatives) }\end{array}$ & $\begin{array}{c}\text { Crop Field } \\
\text { Area (Ha) } \\
\text { (CFA) }\end{array}$ & $\begin{array}{c}\text { Crop Field } \\
\text { Production } \\
\text { (CFP) } \\
\text { (kg/Ha) }\end{array}$ & $\begin{array}{c}\text { Cost of } \\
\text { Production } \\
\text { (CP) } \\
\text { (USD/Ha) }\end{array}$ & $\begin{array}{c}\text { Price of } \\
\text { sale (PS) } \\
\text { USD per } \\
\text { Kg }\end{array}$ \\
\hline 1. & Wheat (C1) & 326000 & 6100 & 350 & 0.4 \\
\hline 2. & Barley (C2) & 4000 & 6000 & 300 & 0.3 \\
\hline 3. & Vegetables (C3) & 109000 & 24700 & 500 & 2 \\
\hline 4. & Fruits (C4) & 233000 & 6900 & 500 & 4 \\
\hline 5. & Fodders (C5) & 161000 & 18500 & 250 & 0.1 \\
\hline
\end{tabular}

The relative significance of the two criteria, rated in the digits from 1 to 9 (Hamidi et al., 2010), is given in Table 3.

Table 3. Relative importance of two Criteria.

\begin{tabular}{|c|c|}
\hline Digits & The relative significance of the two criteria \\
\hline $2,4,6,8$ & Compromised between slightly different judgments \\
\hline 9 & Absolutely more significant \\
\hline 7 & Demonstrably more significant \\
\hline 5 & Strongly more significant \\
\hline 3 & Slightly more significant \\
\hline 1 & Equally significant \\
\hline
\end{tabular}

Table 4 gives the pairwise comparison of the four criteria undertaken here, as given in Table 2.

Table 4. The pairwise comparison of the matrix for criteria.

\begin{tabular}{|c|c|c|c|c|}
\hline & CFA & CFP & CP & PS \\
\hline CFA & 1 & 2 & 2 & 3 \\
\hline CFP & 0.5 & 1 & 0.5 & 0.5 \\
\hline CP & 0.5 & 2 & 1 & 3 \\
\hline PS & 0.33 & 2 & 0.33 & 1 \\
\hline
\end{tabular}


Figure 7 gives the weight of each criterion. To assign an optimum weight to the criteria, a compound weight wk is evaluated from the AHP $\left(\alpha_{k}\right)$, Entropy $\left(\beta_{k}\right)$ weights (Mohammadi et al., 2020). It shows the highest weight is obtained for the CFA from all three methods.

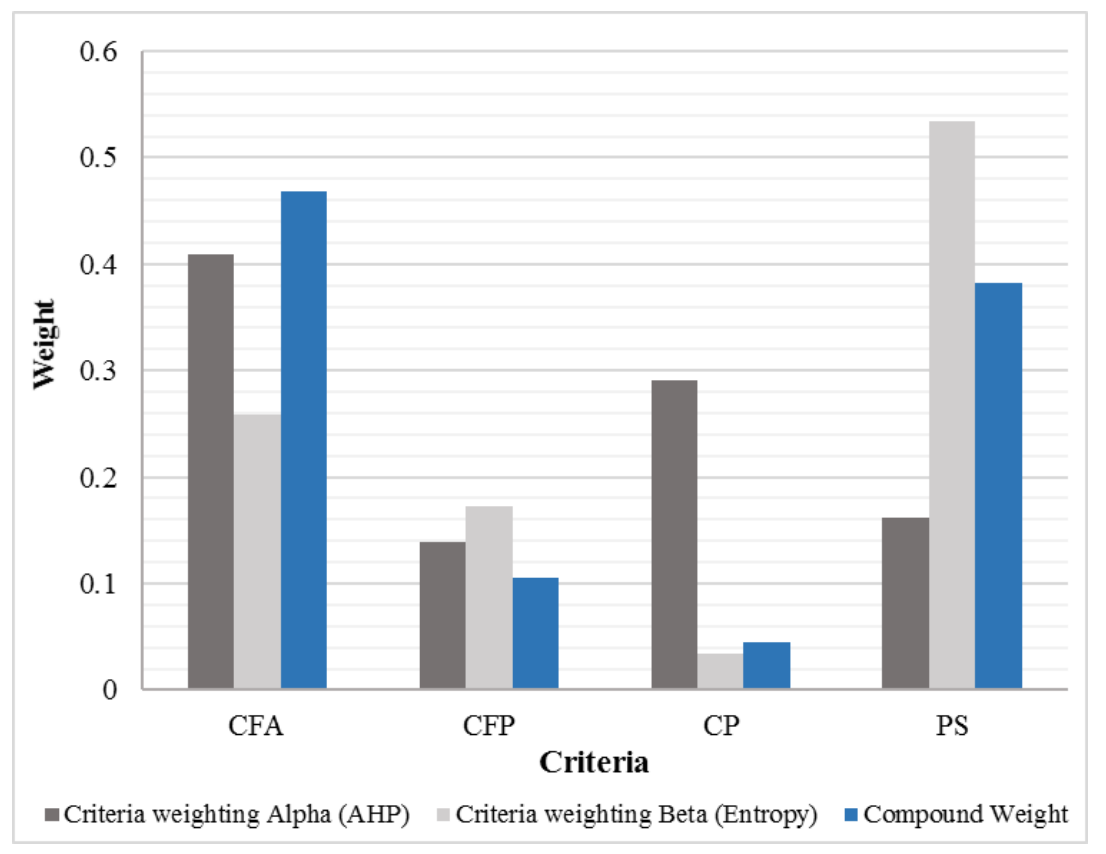

Figure 7. Criteria weight by AHP, Entropy, and compound weight.

Table 5 gives the normalized decision matrix. The numerical values are admitted to the MCDM methods from this normalized decision matrix. These numerical values have no direct relationship with crop ranking.

Table 5. Normalized decision matrix.

\begin{tabular}{|r|l|c|c|c|c|}
\hline S. No. & General crops of KSA & $\begin{array}{c}\text { Crop Field } \\
\text { Area (Ha) } \\
\text { (CFA) }\end{array}$ & $\begin{array}{c}\text { Crop Field } \\
\text { Production } \\
\text { (CFP) (Kg/Ha) }\end{array}$ & $\begin{array}{c}\text { Crop } \\
\text { Production } \\
\text { (CP) } \\
\text { (USD/Ha) }\end{array}$ & $\begin{array}{c}\text { Price of Sale } \\
\text { (PS) USD } \\
\text { per Kg }\end{array}$ \\
\hline 1 & Wheat (C1) & 1 & 0.005347594 & 0.6 & 0.07692308 \\
\hline 2 & Barley (C2) & 0 & 0 & 0.8 & 0.05128205 \\
\hline 3 & Vegetables (C3) & 0.32608696 & 1 & 0 & 0.48717949 \\
\hline 4 & Fruits (C4) & 0.71118012 & 0.048128342 & 0 & 1 \\
\hline 5 & Fodders (C5) & 0.48757764 & 0.668449198 & 1 & 0 \\
\hline
\end{tabular}


Table 6 shows the results of the Exprom-2 method. As per the results, the first rank is for fruits, the second rank is for Wheat, the third rank is for vegetables, the fourth rank is for fodders, and the last rank is for Barley.

Table 6. The positive, negative, and total flow of the $i^{\text {th }}$ alternative using Exprom-2.

\begin{tabular}{|c|c|c|c|c|}
\hline S.No. & $\boldsymbol{\varphi}+(\mathbf{i})$ & $\boldsymbol{\varphi}-(\mathbf{i})$ & $\boldsymbol{\Phi}(\mathbf{i})$ & Ranking \\
\hline 1 & 0.414096619 & 0.238606655 & 0.175489964 & 2 \\
\hline 2 & 0.026562556 & 0.647199505 & -0.62063695 & 5 \\
\hline 3 & 0.342864608 & 0.291066092 & 0.051798515 & 3 \\
\hline 4 & 0.646372118 & 0.136000245 & 0.510371872 & 1 \\
\hline 5 & 0.208557023 & 0.325580424 & -0.11702340 & 4 \\
\hline
\end{tabular}

The numerical values determined from the weighted normalized decision matrix, given in Tables 7 and 8 , are used as inputs in the MCDM techniques.

Table 7. Weighted and normalized decision matrix.

\begin{tabular}{|c|l|c|c|c|c|}
\hline S. No. & Agricultural yields & \multicolumn{1}{|c|}{ CFA } & CFP & CP & PS \\
\hline 1 & Wheat (C1) & 0.731922964 & 0.186207683 & 0.397573284 & 0.088866949 \\
\hline 2 & Barley (C2) & 0.00898065 & 0.183155098 & 0.340777101 & 0.066650212 \\
\hline 3 & Vegetables (C3) & 0.244722709 & 0.753988488 & 0.567961834 & 0.444334746 \\
\hline 4 & Fruits (C4) & 0.523122855 & 0.210628363 & 0.567961834 & 0.888669491 \\
\hline 5 & Fodders (C5) & 0.361471157 & 0.56472822 & 0.283980917 & 0.022216737 \\
\hline
\end{tabular}

Table 8. The ideal and nonideal solutions. 


\begin{tabular}{|l|l|l|l|l|}
\hline & $\begin{array}{c}\text { Crop Field } \\
\text { Area (Ha) } \\
\text { (CFA) }\end{array}$ & $\begin{array}{c}\text { Crop Field } \\
\text { Production(CFP) } \\
\text { (Kg/Ha) }\end{array}$ & $\begin{array}{c}\text { Cost of Production } \\
\text { (CP) (USD/Ha) }\end{array}$ & $\begin{array}{c}\text { Price of Sale } \\
\text { Price (PS) USD } \\
\text { per Kg }\end{array}$ \\
\hline $\boldsymbol{V}_{\boldsymbol{J}+}$ & 0.342516497 & 0.079893841 & 0.012572098 & 0.339293562 \\
\hline $\boldsymbol{V}_{\boldsymbol{J}-}$ & 0.004202656 & 0.019407411 & 0.025144196 & 0.008482339 \\
\hline
\end{tabular}

The results of the TOPSIS method are depicted in Table 9. The highest $C_{i}$ value corresponds to rank first, followed by second, third, fourth, and fifth. So, the sequence of ranking in this research work is fruits> Wheat $>$ vegetables $>$ fodder $>$ barley, and this result is consistent with Exprom-2 (Table 6). Hence, the result is validated.

Table 9. The alternative prioritization of different criteria using TOPSIS.

\begin{tabular}{|l|l|l|l|l|l|l|}
\hline S. No. & \multicolumn{1}{|c|}{$\begin{array}{c}\text { Kharif Crop } \\
\text { Types }\end{array}$} & \multicolumn{1}{|c|}{$\mathbf{S}_{\mathbf{i}}^{+}$} & \multicolumn{1}{|c|}{$\mathbf{S}_{\mathbf{i}}^{-}$} & \multicolumn{1}{|c|}{ Sum } & \multicolumn{1}{|c|}{$\mathbf{C}_{\mathbf{i}}$} & Rank \\
\hline 1 & Wheat (C1) & 0.311275073 & 0.339353519 & 0.650628591 & 0.521577937 & 2 \\
\hline 2 & Barley (C2) & 0.465425439 & 0.019721998 & 0.485147437 & 0.040651555 & 5 \\
\hline 3 & Vegetables (C3) & 0.284463358 & 0.20445789 & 0.488921248 & 0.418181641 & 3 \\
\hline 4 & Fruits (C4) & 0.114107683 & 0.409064665 & 0.523172348 & 0.781892749 & 1 \\
\hline 5 & Fodders (C5) & 0.374021101 & 0.170301855 & 0.544322957 & 0.31286914 & 4 \\
\hline
\end{tabular}

Table 10 shows the results of the Vikor method, where all the standard parameters are calculated. This ranking is based on the Pi value, the lowest of this value. The highest is the rank. So, the first ranked alternative is fruits, the second is Wheat, the third is vegetables, the fourth is fodder, and the last one fifth is Barley. It is again observed that the ranks of the crops are consistent among all three methods.

Table 10. The $E_{i}, F_{i,}$ and $P_{i}$ are the parameters of the VIKOR method.

\begin{tabular}{|c|l|c|c|c|c|}
\hline S. No. & Crop Type & $\boldsymbol{E i}$ & $\boldsymbol{F i}$ & $\boldsymbol{P i}$ & Rank \\
\hline 1 & Wheat (C1) & 0.475533652 & 0.352430302 & 0.473283028 & 2 \\
\hline 2 & Barley (C2) & 0.945003798 & 0.46796796 & 1 & 5 \\
\hline 3 & Vegetables (C3) & 0.555435251 & 0.315369712 & 0.477707015 & 3 \\
\hline 4 & Fruits (C4) & 0.280291236 & 0.135158448 & 0 & 1 \\
\hline 5 & Fodders (C5) & 0.656728401 & 0.381799494 & 0.653701719 & 4 \\
\hline
\end{tabular}


The comparative ranks of the crops obtained from the TOPSIS, EXPROM2, and the VIKOR methods are represented in Figure 8.

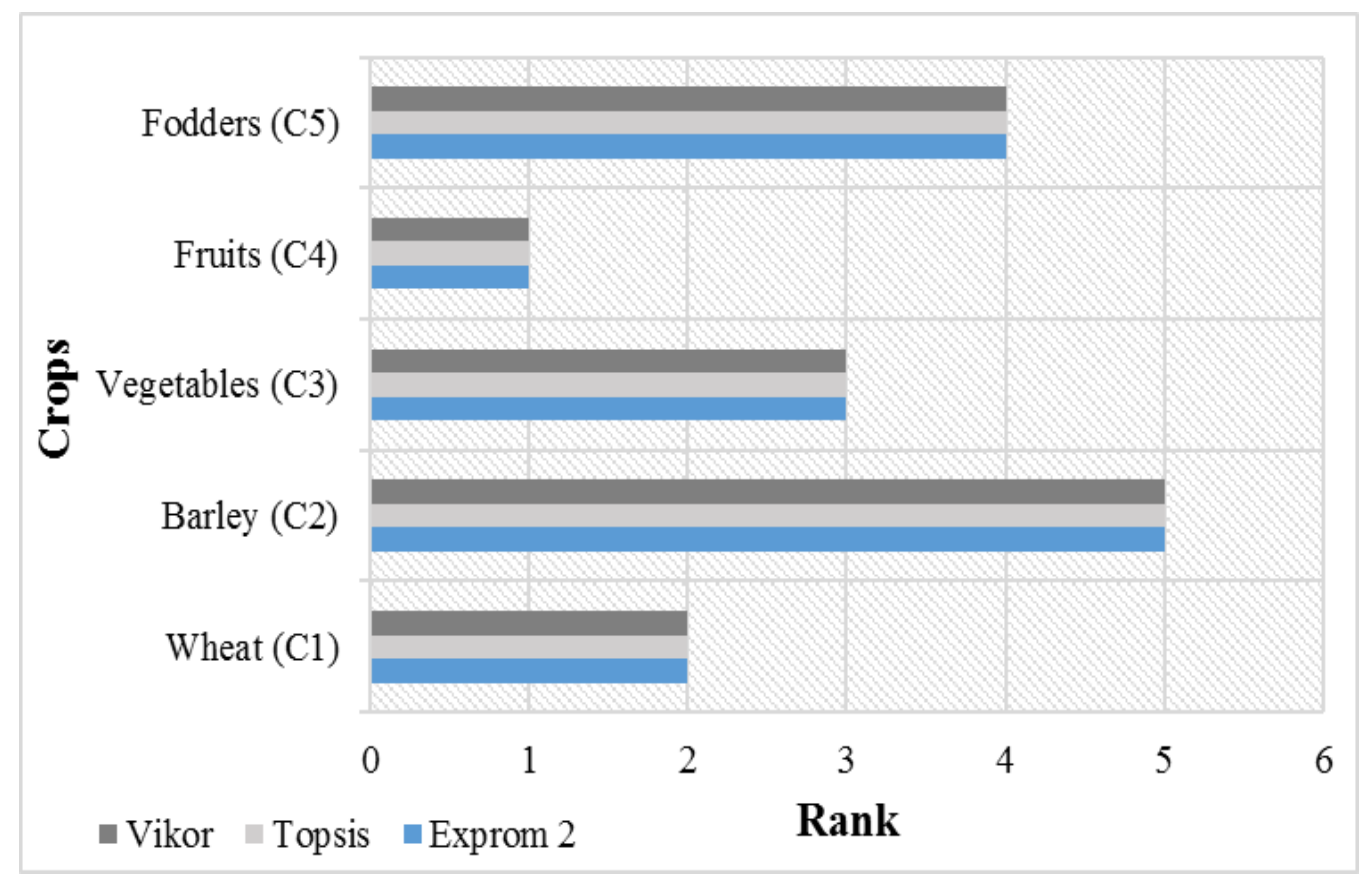

Figure 8. Crop ranks obtained from VIKOR, EXPROM2, and TOPSIS MCDM methods.

There is a $100 \%$ match between the results of the three methods. Therefore, it emerges from the study that, in the interest of the farmers, crops shall be selected in preferential order of their ranks. MCDM emerges as a useful tool to calculate the most preferred crop.

The future scope of MCDM techniques is unlimited. Selection of material and processes for biomass pyrolysis (Singh et al., 2017) is one such attactive area, in which authors are planning to extend their work.

\section{CONCLUSION}

The KSA has a predominantly arid region, with less annual average rainfall. The general crops grown in southwest KSA are ranked using the MCDM model. The local sustainability parameters, i.e., the climatic factors and the socioeconomic conditions, are kept in mind. The criteria chosen in the ranking process are farm area, water requirement; crop yield; production cost; and the crop yield's market value. The Entropy and AHP techniques were used for the analysis of the crops employing the compromised weighing technique. Three MCDM techniques were employed to determine the most productive crop using TOPSIS, VIKOR, and Exprom-2. The results obtained by the three techniques are in absolute agreement for crop prioritization. The results indicate that the crops' priority shall be fruits, Wheat, vegetables, fodders, and Barley. It is suggested that the system-oriented techniques be developed by integrating MCDM and being employed to select the best crop. More opinions include the more significant criteria based on sustainability and ecological perspectives to improve the basic policy and framing process. This study's research outcome shall be directly beneficial to the stakeholders for maximizing productivity, effective policymaking, and sustainable farming practices. 


\section{ACKNOWLEDGMENT}

The authors thankfully acknowledged the support and funding provided by the Scientific Research Deanship, King Khalid University, Abha, Asir, Kingdom of Saudi Arabia, under the Research Group Program, under the grant number R.G.P1./201/41.

\section{NOMENCLATURE}

\begin{tabular}{|ll|}
\hline Multiple criteria decision-making model & MCDM \\
\hline Gross domestic product & GDP \\
\hline Food and Agriculture Organization & FAO \\
\hline Kingdom of Saudi Arabia & KSA \\
\hline The Technique for Order of Preference by Similarity to Ideal Solution & TOPSIS \\
\hline VlseKriterijumska Optimizacija I Kompromisno Resenje & VIKOR \\
\hline The Extended PROMETHEE II & Exprom2 \\
\hline Analytic Hierarchy Process & AHP \\
\hline Consistency index & CI \\
\hline Consistency ratio & CR \\
\hline
\end{tabular}

Inamuin Lunsistency muex N

\section{TABLE OF SYMBOLS}

\begin{tabular}{|ll|}
\hline $\mathrm{k}$ & Criteria \\
\hline$w_{k}$ & Synthesis weight \\
\hline$\alpha_{\mathrm{k}}$ & Weight for $\mathrm{k}^{\text {th }}$ criteria, computed from AHP method \\
\hline$\beta_{k}$ & Weight for $\mathrm{k}^{\text {th }}$ criteria, computed from Entropy method \\
\hline $\mathrm{A}$ & Matrix \\
\hline $\mathrm{a}_{1}, \mathrm{a}_{2}, \ldots, \mathrm{a}_{\mathrm{n}}$ & Criterion \\
\hline$\lambda_{\max }$ & Highest eigen value of matrix A \\
\hline$n$ & Number of criteria (evaluation indexes) \\
\hline$m$ & Alternatives (choices) \\
\hline$x_{11}, x_{1 n}, x_{m n}$ & Evaluation indeces \\
\hline$P_{i j}$ & Normalized vector, a proportion of $i^{t h}$ index under index $j$ \\
\hline$E_{j}$ & Entropy of the $j^{\text {th }}$ criteria \\
\hline
\end{tabular}




\begin{tabular}{|c|c|c|}
\hline \multicolumn{2}{|l|}{$d_{j}$} & Degree of divergence \\
\hline \multicolumn{2}{|c|}{$\beta_{j}$} & Weight of entropy of $j^{\text {th }}$ criteria \\
\hline \multicolumn{2}{|c|}{$\varphi^{+}(i)$} & Positive flow for the $i^{\text {th }}$ alternative \\
\hline \multicolumn{2}{|c|}{$\varphi^{-}(i)$} & Negative flow for the $i^{\text {th }}$ alternative \\
\hline \multicolumn{2}{|c|}{$\varphi(i)$} & Total outranking flow \\
\hline \multicolumn{2}{|c|}{$\left(x_{i j}\right)_{m x n}$} & $\begin{array}{l}\text { Matrix formed by } \mathrm{n} \text { criteria and } \mathrm{m} \text { alternatives with the } \\
\text { intersection of each alternative and criteria given by } x_{i j}\end{array}$ \\
\hline \multicolumn{2}{|l|}{$R$} & Normalized matrix \\
\hline \multicolumn{2}{|c|}{$r_{i j}$} & Normalized value of $x_{i j}$ \\
\hline \multicolumn{2}{|l|}{$T$} & Resultant of matrix operation \\
\hline \multicolumn{2}{|l|}{$t_{i j}$} & Matrix element corresponding to $i^{\text {th }}$ row and $j^{\text {th }}$ column \\
\hline \multicolumn{2}{|c|}{$W_{j}$} & Original weight is given to the indicator $v_{j}$ \\
\hline \multicolumn{2}{|c|}{$v_{j}$} & Standard value of indicator \\
\hline \multicolumn{2}{|c|}{$A_{w}$} & Worst alternative \\
\hline \multicolumn{2}{|c|}{$A_{b}$} & Best alternative \\
\hline \multicolumn{2}{|c|}{$J_{+}$} & Positive impact (benefit criteria) \\
\hline \multicolumn{2}{|c|}{$J_{-}$} & Negative impact (cost criteria) \\
\hline \multirow[t]{5}{*}{ y } & $u_{i w}$ & 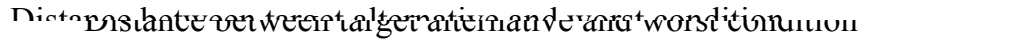 \\
\hline & $d_{i b}$ & Distance between target alternative and best condition \\
\hline & $S_{i w}$ & Similarity to the worst condition \\
\hline & $E_{i}, F_{i}$, and $P_{i}$ & Standard parameters of the VIKOR method \\
\hline & $\vartheta$ & $\begin{array}{l}\text { Weight of the strategy of the majority of the criteria } \\
\text { (decision mechanism index) ranging between } 0 \text { and } 1\end{array}$ \\
\hline
\end{tabular}

\section{REFERENCES}

Agarwal, R. \& Garg, P.K. 2016. Remote sensing and GIS based groundwater potential \& recharge zones mapping using multi-criteria decision making technique. Water Resour. Manag., 30, 243-260.

Aleisa, E., Alshayji, K. 2019. Analysis on reclamation and reuse of wastewater in Kuwait. J. Eng. Res. 7(1), 113.

Bailey, R. \& Willoughby, R. 2013. Edible oil: food security in the Gulf. Chatham House., 1-16.

Behzadian, M., Kazemzadeh, R.B., Albadvi, A. \& Aghdasi, M. 2010. PROMETHEE: A comprehensive literature review on methodologies and applications. Eur J Oper Res., 200, 198-215.

Bhangale, P.P., Agrawal, V.P. \& Saha, S.K. 2004. Attribute based specification, comparison, and selection of a robot. Mech Mach Theory., 39, 1345-1366. 
Carroll, S., Liu, A., Dawes, L., Hargreaves, M. \& Goonetilleke, A. 2013. Role of land use and seasonal factors in water quality degradations. Water Resour. Manag., 27, 3433-3440.

Chatterjee, P. \& Chakraborty, S. 2012. Material selection using preferential ranking methods. Mater. Des., 35 , 384-393.

Chitsaz, N. \& Banihabib, M.E. 2015. Comparison of different multi-criteria decision-making models in prioritizing flood management alternatives. Water Resour. Manag., 29, 2503-2525.

Chu, J. \& Su, Y. 2012. The application of TOPSIS method in selecting fixed seismic shelter for evacuation in cities. Syst. Eng. Procedia., 391-397.

Cocklin, C.R. 2009. Agriculture, society, and environment: discourses on sustainability. - Int J Sust Dev World. 2, 240-256.

Dağdeviren, M., Yavuz, S. \& Kılınç, N. 2009. Weapon selection using the AHP and TOPSIS methods under fuzzy environment. Expert Systems with Applications, 36, 8143-8151.

Dillon, E.J., Hennessy, T.C. \& Hynes, S. 2009. Towards measurement of farm sustainability-an Irish case study. International Association of Agricultural Economists Conference, Beijing, China, 1-21.

Doumpos, M. \& Zopounidis, C. 2004. A multicriteria classification approach based on pairwise comparisons. Eur J Oper Res., 158, 378-89.

Garg, N.K. \& Dadhich, S.M. 2014. Integrated non-linear model for optimal cropping pattern and irrigation scheduling under deficit irrigation. Agr Water Manage., 140, 1-13.

Garg, R.K., Agrawal, V.P. \& Gupta, V.K. 2007. Coding, evaluation, and selection of thermal power plants-A MADM approach. Int J Elec Power., 29, 657-668.

General crop pattern Saudi Arabia. 2019. https:/www.slideshare.net/WaterforLife/nonrenewable-groundwater-management-in-saudi-arabia/26Location_of_main_consumers_Conflict. (assessed on 25.07.2019)

Geng, G. \& Wardlaw, R. 2013. Application of multi-criterion decision making analysis to integrated water resources management. Water Resour. Manag., 27, 3191-3207.

Gowda, M.C. \& Jayaramaiah, K.M. 1998. Comparative evaluation of rice production systems for their sustainability. Agric Ecosyst Environ., 69, 1-9.

Hamidi, N., Pezeshki, P.M. \& Moradian, A. 2010. Weighting the criteria of brand selecting in beverage industries in Iran. Asian Journal of Management Research, 1, 250-267.

https://doi.org/10.1080/13504509509469905

Hendiani, S., Mahmoudi, A. \& Liao, H. 2020. A Multi-Stage Multi-Criteria Hierarchical Decision-Making Approach for Sustainable Supplier Selection. Applied Soft Computing Journal 94 (106456): 1-19.

Kamran, M.A., Khoshsirat, M., Mikaeil, R., Nikkhoo, F. 2017. Ranking the saw ability of ornamental and building stones using different MCDM methods. J. Eng. Res. 5(3), 125-149.

Madhu, P., Dhanalakshmi, C.S. \& Mathew, L. 2020. Multi-Criteria Decision-Making in the Selection of a Suitable Biomass Material for Maximum Bio-Oil Yield during Pyrolysis. Fuel 277 (118109): 1-12.

Ministry of Agriculture, Kingdom of Saudi Arabia, Riyadh. 2019.

Mohammadi, M. \& Rezaei, J. 2020. Ensemble Ranking: Aggregation of Rankings Produced by Different. Omega 96 (102254): 1-12.

Mutikanga, H.E., Sharma, S.K. \& Vairavamoorthy, K. 2011. Multi-criteria decision analysis: a strategic planning tool for water loss management. Water Resour. Manag., 25, 3947-3969.

Nambiar, K.K.M., Gupta, A.P., Fu, Q. \& Li, S. 2001. Biophysical, chemical and socio-economic indicators for assessing agricultural sustainability in the Chinese coastal zone. Agric Ecosyst Environ., 87(2), 209-214.

Peacock, C. \& Sherman, D.M. 2010. Sustainable goat production-Some global perspectives. Small Rumin Res., 89 (2-3), 70-80. doi:10.1016/j.smallrumres.2009.12.029.

Pramanik, M.K. 2016. Site suitability analysis for agricultural land use of Darjeeling district using AHP and GIS techniques. Model. Earth Syst. Environ., 2:56. 1-22. 
Qureshi, M.R., Singh, R.K. \& Hasan, M.A. 2018. Decision support model to select crop pattern for sustainable agricultural practices using fuzzy MCDM. Environ Dev Sustain., 20(2, 641-659.

Raju, K.S. \& Kumar, D.N. 1999. Multicriterion decision making in irrigation planning. Agr Syst., 62, 117-129.

Raju, K.S. \& Vasan, A. 2007. Multi attribute utility theory for irrigation system evaluation. Water Resour. Manag., 21, 717-728.

Raju, K.S., Duckstein, L. \& Arondel, C. 2000. Multicriterion analysis for sustainable water resources planning: a case study in Spain. Water Resour. Manag., 14, 435-456.

Rao, P.V. \& Baral, S.S. 2011. Attribute based specification, comparison and selection of feed stock for anaerobic digestion using MADM approach. J. Hazard. Mater., 186 (2-3), 2009-2016.

Rao, R.V. \& Patel, B.K. 2010. A subjective and objective integrated multiple attribute decision-making method for material selection. Mater. Des., 31, 4738-4747.

Roozbahani, A., Zahraie, B. \& Tabesh, 2012. M. PROMETHEE with precedence order in the criteria (PPOC) as a new group decision making aid: an application in urban water supply management. Water Resour. Manag., 12, 3581-3599.

Roy, R. \& Chan, N.W. 2012. An assessment of agricultural sustainability indicators in Bangladesh: review and synthesis. The Environmentalist., 32, 99-110.

Singh, R.K., Mallick, J., Hasan, M.A., Mohamed, M.H. 2019. Simulation based ranking of vegetable cash crops for sustainable greenhouse farming practices. Applied Ecology and Environmental Research 17:4615-4629.

Singh, S., Gautam, A., Gautam, S. 2017. An experimental investigation on isothermal pyrolysis of soybean husk. J. Eng. Res. 5(4), 19-30.

Song, J.Y. \& Chung, E.S. 2016. Robustness, uncertainty and sensitivity analyses of the TOPSIS method for quantitative climate change vulnerability: A case study of flood damage. Water Resour. Manag., 13, 47514771.

Sorensen, A.A., Van Beest, F.M. \& Brook, R.K. 2015. Quantifying overlap in crop selection patterns among three sympatric ungulates in an agricultural landscape. BASIC APPL ECOL., 16, 601-609.

Srdjevic, B., Medeiros, Y.D. \& Faria , A.S. 2004. An objective multi-criteria evaluation of water management scenarios. Water Resour. Manag., 18, 35-54.

Srinivas, R., Singh, A.P. \& Sharma, R. 2017. A scenario based impact assessment of trace metals on ecosystem of river Ganges using multivariate analysis coupled with fuzzy decision-making approach. Water Resour. Manag., 31, 4165-4185.

Sydorovych, O.\& Wossink, A. 2008. The meaning of agricultural sustainability: Evidence from a conjoint choice survey. AGR SYST., 98, 10-20.

Venkata Rao R. 2008. Evaluating flexible manufacturing systems using a combined multiple attribute decision making method. Int J Prod Res., 46(7), 1975-1989.

Warrag, E.I., Mallick, J., Singh, R.K. \& Khan, R.A. 2019. Status of dieback of Juniperus Procera (African Pencil Cedar) in natural stands and plantation in Alsouda highlands, Saudi Arabia. Applied Ecology and Environmental Research 17(2): 2325-2338.

Wind, Y. \& Saaty, T.L. 1980. Marketing applications of the analytic hierarchy process. Management science. 26, 641-658.

Xu, Y., Li, Y., Zheng, L., Cui, L., Li, S., Li, W. \& Cai, Y. 2020. Site Selection of Wind Farms Using GIS and Multi-Criteria Decision Making Method in Wafangdian, China. Energy 207 (118222): 1-12.

Zhen, L., Routray, J.K., Zoebisch, M.A., Chen, G., Xie, G. \& Cheng, S. 2005. Three dimensions of sustainability of farming practices in the North China Plain: a case study from Ningjin County of Shandong Province, PR China. Agric Ecosyst Environ., 105, 507-522.

Zhen, L., Zoebisch, M.A., Chen, G. \& Feng, Z. 2006. Sustainability of farmers' soil fertility management practices: A case study in the North China Plain. J Environ Manage., 79(4), 409-419. 